\title{
Modelling IoT-enabled Logistics Process Adaptations with Coloured Petri Nets
}

\author{
Xiaoqin Dong \\ School of Economics and Management \\ Beijing Jiaotong University \\ Beijing, China
}

\author{
Ying Wang \\ School of Economics and Management \\ Beijing Jiaotong University \\ Beijing, China
}

\begin{abstract}
The Internet of Things not only supports intelligent logistics services, but also transforms the process. It has become more and more widely used. This paper studied the railway transportation process according to the development of the Internet of Things technology in the railway logistics industry. And the paper takes transport cotton as an example, in the process of cotton transportation, a real-time security monitoring system composed of IoT technology was added. The colored Petri net was used to model the simulation flow. Time concept is added to the CPN models to capture the time taken by the service activities for the investigation of the performance of the service systems. Finally, two different process models are analyzed and compared. Finally, two different process models are analyzed and compared. Provide effective basis for management decisions.
\end{abstract}

Keywords-internet of things; colored Petri net; railway logistics; cotton transport

\section{INTRODUCTION}

Efficient delivery of logistics services has always been considered vital to build competitive economies [1]. Despite the long history of logistics as a business function, current information technologies have provided fundamental contributions to improve the logistics service systems [2]. The Internet of Things (IoT) is such a novel paradigm, which will have a high impact on logistics field, with the ability to connect and integrate varieties of things to create an autonomous environment for smart service delivery [3][4]. It is expected to gain considerably from the new logistics concepts using IoT for both performance growth and cost savings [5].

Logistics service is defined as the process of delivering products and/or services to customers, in a way that creates added value to customers [14]. It is considered as a central element of the marketing strategy for companies that can be used to create added value. Currently, logistics has become a major business function for cargo handling and transportation [2]. Traditionally, logistics is highly human-centered in nature, with most operations executed manually [15][16]. The manually controlled logistics operations cause large risks and uncertainties for the logistics service delivery.

Internet of Things (IoT) is one of the core technologies in the "fourth industrial revolution" [17], with the power of interconnecting the objects in the real world [18]. Internet connectivity has extended to everyday objects with IoT technologies [19]. Physical real world 'things' or objects are embedded with sensors, allowing for automatic data collection and exchange between the physical and the virtual world. Traditional manual logistics operations can largely be replaced by automatic procedures thereby, thanks to the use of the ubiquitous IoT technologies. As such, the new IoT paradigm has enabled the formation of the smart logistics service.

However, existing academic work mainly concentrated on the technical perspective in science and engineering fields, with much more focus on the technological implementations of IoT supported logistics systems [6][7][8]. Regarding the delivery of efficient and high-quality smart services, which is the main goal of the IoT paradigm [4], there are far fewer academic studies. How is the performance of IoT supported e-services? How does the Internet of things change processes? How to make decisions and optimize processes under the Internet of things? There is not enough research in this area. A better understanding is needed to improve the IoT applications in logistics through an effective analysis of the e-services.

For the intangible services without a physical manifestation [9], an investigation into the operational processes would provide valuable insights for the service delivery [10]. Colored Petri nets (CPNs), a discrete-event modelling language combining Petri nets with a programming language, provides an industrial-strength framework for system analysis and simulation [11][12]. This would serve well as a basis for the exploration and analysis of a service system [13]. As such, we propose to use a novel CPN based method for the modelling and investigation of the IoT supported logistics services. The method will be illustrated using a case study for rail freight transportation.

The remainder of this paper is organized as follows. The next section will elaborate on the IoT enabled smart logistics service. In Section 3, the CPN based approach is presented after a discussion about related CPN concepts. Section 4 presents the model and Section 5 provides the model based analysis and comparison for the logistics services. The paper will be concluded in Section 6

\section{THE METHOD}

The Colored Petri net $(\mathrm{CPN})$ is a comprehensive framework for system construction and analysis proposed by Kurt Jensen [20]. CPN combines the graphical representation of Petri nets with strength of programming languages. By 
means of a CPN model, distributed and concurrent systems can be represented, simulated and visualized, supporting a thorough investigation into the considered system.

\section{A. CPN Model}

A CPN model can be formally defined as a nine-tuple:

$$
\mathrm{CPN}=(\Sigma, \mathrm{P}, \mathrm{T}, \mathrm{A}, \mathrm{C}, \mathrm{G}, \mathrm{E}, \mathrm{I})
$$

Where $\Sigma$ is the colour set, $\mathrm{P}$ is the set of places, $\mathrm{T}$ is the set of transitions, A is the set of directed arcs, $\mathrm{C}$ is the colour function, $G$ is the guard function, $E$ is the arc expression function, and $\mathrm{I}$ is the initialization function.

Hence, the basic constructs of a CPN model consist the following elements:

- Places. Places represent the states of a CPN model, shown as ellipses or circles in the graphical drawing.

- Colour set. A colour set is associated with each place, indicating the type of data contained by the place.

- Colour function. Each place can have a number of tokens, carrying token values called token colors. The color function is used to distinguish the token colors.

- Transitions. Transitions are drawn as rectangles in the graphical drawing, representing the actions of a CPN model.

- Guard function. The condition of a transition is expressed using a guard function.

- Arcs. In a CPN model, transitions and places are connected with a set of directed arcs.

- Arc expression function. The arc expressions are positioned next to the arcs, determining the number of token changes caused by the occurrence of a transition.

- Initialization function. The initialization function is used to describe the initial state of places.

\section{B. CPN Based on Exploration of IoT-enabled Logistics \\ Services}

As such, we propose to employ a CPN based method for the investigation of IoT-enabled logistics services. First, we will describe the operational processes for the service deliveries with IoT-enabled services. Next, the processes will then be modelled using Coloured Petri net, with transitions, places, colour set, and functions defined. Third, as CPN models are executable, the behaviour of the service system is investigated through simulations of the CPN models. Finally, the analysis and comparison can then be performed on the basis of the simulation results. The method is illustrated in "Fig. 1".

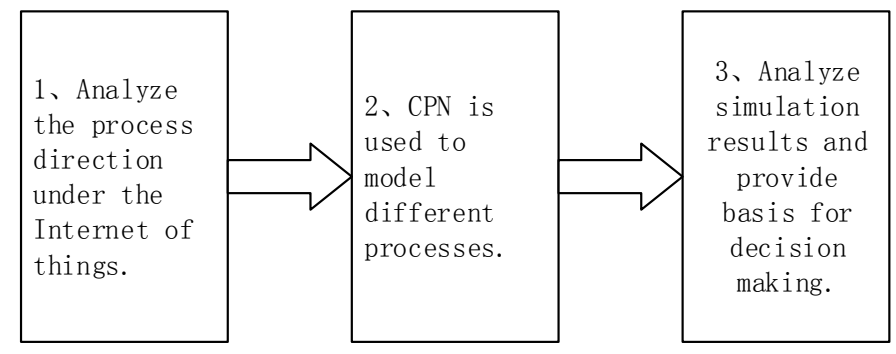

Fig. 1. CPN based method for the investigation of IoT-enabled logistics services.

\section{THE CASE SCENARIO}

Current fragmented and specialized railway systems are becoming ever more complex [21]. During the long-distance transportation by freight trains, a number of uncertainties and risks are involved in the railway logistics service delivery [22]. In this paper, we will take the railway transportation for cotton, one of the most important industrial crops, and a typical flammable material, as the scenario.

In China, places of production and consumption for cotton are often scattered in a large area. For example, Xinjiang, a major production area for cotton, is approximately 5,000 kilometers away from Zhejiang Province, which is an important cotton consumption area. Therefore, railway composes a primary transportation means for cotton delivery. A number of factors (e.g. temperature, humidity, photo electricity, and friction) have a crucial influence on the cotton transportation process by railway. For example, an increasing moisture regain will cause the cotton prone to deterioration, leading to a lower cotton quality. In addition, increasing heat caused by cotton oxidation will result in a spontaneous combustion, which may threaten the railway transporation safety.

The IoT provides a viable solution for collecting and monitoring the state of objects [23]. With the sensing capabilities, it is expected that process executions can identify the situation and make adaptations accordingly [24]. In the case of cotton transportation by railway, IoT techniques have been adopted to trace the cotton status (e.g. temperature, moisture). Process adaptations will then be decided. For example, the cotton package can be unloaded and re-treated before transported to the original destination. Or, in another case, the cotton is unloaded and sold where the abnormality is reported by the sensors. As such, a modelling and simulation analysis is needed for an accurate evaluation of different process adaptation decisions.

\section{MODELLING AND SimUlation}

In this section, we will employ the Colored Petri net to model the operational processes for IoT-enabled logistics service delivery. Simulation is then conducted for the analytics of different decisions for process adaptations. 


\section{A. Different Decisions for Process Adaptations}

Different process adaptations need to be decided based on the situational changes identified by IoT devices ${ }^{[25]}$. Assuming that an alert may be created in Lanzhou for a too high humidity during the cotton transportation from Urumchi to Hangzhou. A reduced cotton quality is therefore expected due to oxidative deterioration. In this case, different process adaptations are to be decided which will be elaborated in the following sections.

Suppose that the cotton can be sold at a lower price in the local market in Lanzhou where the alarm is reported. As such, decisions should be made regarding whether to change the transport destination to Lanzhou. We will then conduct the analytics through process modelling and simulation.

\section{B. Modelling the Process for Proceeding to the Original Destination}

When the sensors raise the alarm during the cotton transportation process, the railway carrier will notify the consigner that the humidity of cotton may be too high. The consigner may decide that the cotton would be transported to the original destination after some re-handling work. In this case, the railway wagon would be uncoupled from the original locomotive. The cotton would then be unloaded and delivered to the railway goods yard for the re-treatment. Afterwards, the cotton would be loaded and coupled to another locomotive to the original destination.

"Fig. 2" shows the CPN model for the adaptive process if the consigner would proceed the transportation to the original destination.

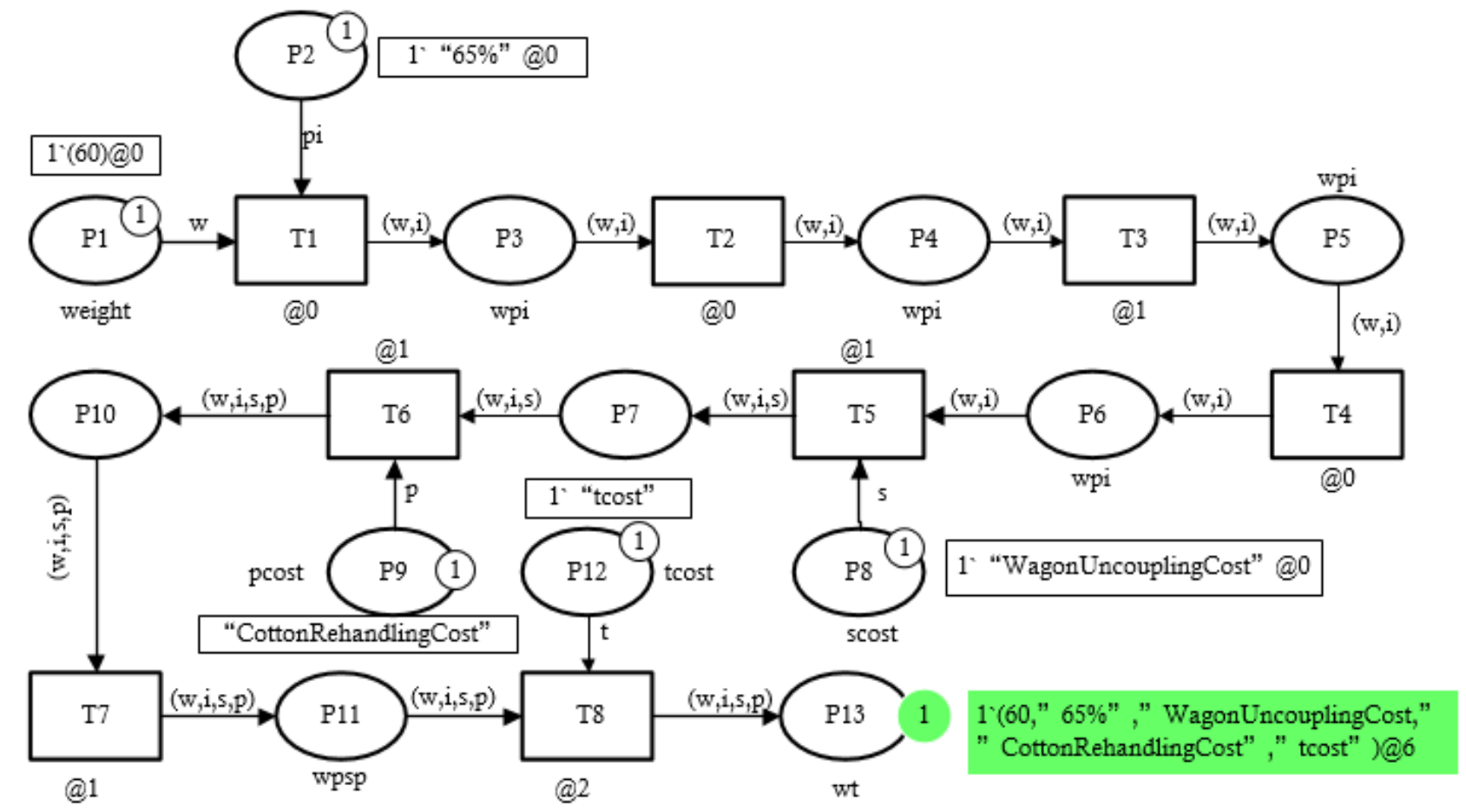

Fig. 2. CPN model for the adaptive process of proceeding the transportation to the original destination.

"Table I" illustrates the transitions and places used in this model.

TABLE I. TRANSITIONS AND PLACES IN THE CPN MODEL FOR THE PROCESS OF PROCEEDING TO THE TRANSPORT DESTINATION

\begin{tabular}{|l|l|}
\hline \multicolumn{1}{|c|}{$\begin{array}{c}\text { Places } \\
\text { /Transitions }\end{array}$} & \multicolumn{1}{c|}{ Description } \\
\hline P1 & Cotton loading and ready for transportation \\
\hline P2 & Initial state of normal humidity \\
\hline P3 & Sensors started \\
\hline P4 & Humidity out of range \\
\hline P5 & Consigner notified \\
\hline P6 & Ready for the wagon uncoupling \\
\hline P7 & Cotton delivered to the railway goods yard \\
\hline P8 & Cost incurred for the wagon uncoupling \\
\hline P9 & Cost incurred for the cotton rehandling \\
\hline P10 & Cotton reloaded \\
\hline P11 & Ready for re-transportation \\
\hline
\end{tabular}

\begin{tabular}{|l|l|}
\hline $\begin{array}{c}\text { Places } \\
\text { /Transitions }\end{array}$ & \multicolumn{1}{c|}{ Description } \\
\hline P12 & Cost incurred for the re-transportation \\
\hline P13 & Original destination arrived \\
\hline T1 & Starting transportation \\
\hline T2 & Sensors monitoring \\
\hline T3 & Raising the alarm \\
\hline T4 & Deciding to proceed to the original destination \\
\hline T5 & Uncoupling the wagon \\
\hline T6 & Cotton rehandling work in the railway goods yard \\
\hline T7 & Coupling the wagon to another locomotive \\
\hline T8 & Proceeding the transportation \\
\hline
\end{tabular}

The color set is defined as follows:

colset weight = int timed;

colset pi = string timed;

colset scost = string timed; 
colset $w p s=$ product weight $*$ pi ${ }^{*}$ scost timed;

colset tcost $=$ string timed;

colset wpi $=$ product weight $*$ pi timed;

colset pcost $=$ string timed;

colset $w t=$ product weight ${ }^{*}$ pi ${ }^{*}$ scost ${ }^{*}$ pcost ${ }^{*}$ tcost timed;

var $w:$ weight; var $s:$ scost;

var $i:$ pi; var $p:$ pcost; var $t:$ tcost;

where

- weight represents the weight of the cotton, defined as an integer type.

- $\quad$ pi represents the humidity, defined as a character type.

- scost represents the cost incurred by the wagon uncoupling.

- $w p s$ is defined as the product color set, representing the product of cotton weight, humidity and wagon uncoupling cost.

- tcost represents the transportation cost, defined as a character type.

- $\quad w p i$ is defined as the product color set, representing the product of cotton weight and humidity.

- pcost represents the cotton re-handling cost, defined as a character type.
- wpsp is defined as the product color set, representing the product of cotton weight, humidity, wagon uncoupling cost, and cotton re-handling cost.

- $w t$ is defined as the product color set, representing the product of cotton weight, humidity, wagon uncoupling cost, cotton re-handling cost, and transportation cost.

- The variables $w, s, i, p$, and $t$ belong to these color sets.

In addition, the time color set is added in the CPN model. "Table II" shows the time cost for the different tasks in the process.

TABLE II. TIME SPENT For THE PROCESS TASKS

\begin{tabular}{|l|l|}
\hline \multicolumn{1}{|c|}{ Task } & \multicolumn{1}{c|}{ Time spent } \\
\hline Transportaion from Urumchi to Lanzhou & 1 day \\
\hline Wagon uncoupling & 1 day \\
\hline Cotton rehandling & 1 day \\
\hline Wagon recoupling and waiting & 1 day \\
\hline Transportation from Lanzhou to Hangzhou & 2 days \\
\hline
\end{tabular}

As such, it will take 6 days for the adaptive process if the consigner decides to proceed the transportation to the original destination.

\section{Modelling the Process for Changing the Transport Destination}

"Fig. 3" shows the CPN model for the adaptive process if the consigner asks the railway carrier to change the destination.

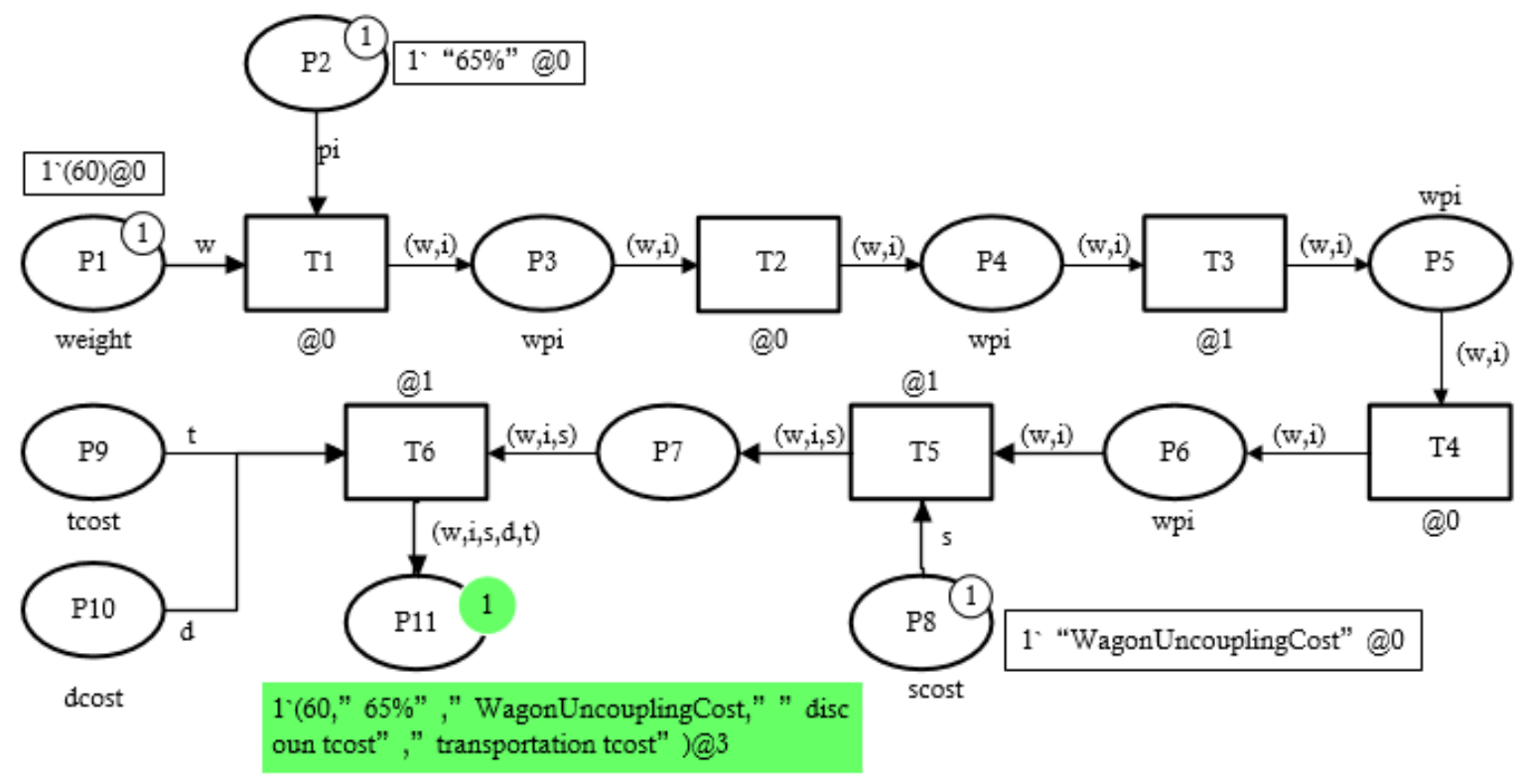

Fig. 3. CPN model for the adaptive process of changing the transport destination.

In this case, the wagon will be uncoupled from the original locomotive at the railway station. After the unloading of the cotton, the consigner will contact other logistics companies to transport the cotton to the local market in Lanzhou for sale.
"Table III" illustrates the transitions and places used in this model. 
TABLE III. TRANSITIONS AND PlaCES IN THE CPN MODEL OF CHANGING THE TRANSPORT DESTINATION

\begin{tabular}{|l|l|}
\hline \multicolumn{1}{|c|}{$\begin{array}{c}\text { Places } \\
\text { /Transitions }\end{array}$} & \multicolumn{1}{c|}{ Description } \\
\hline P1 & Cotton loading and ready for transportation \\
\hline P2 & Initial state of normal humidity \\
\hline P3 & Sensors started \\
\hline P4 & Humidity out of range \\
\hline P5 & Consigner notified \\
\hline P6 & Ready for the wagon uncoupling \\
\hline P7 & Local logistics companies contacted \\
\hline P8 & Cost incurred for the wagon uncoupling \\
\hline P9 & Cost incurred for the cotton transportation \\
\hline P10 & Cost incurred for the cotton sale at a reduced price \\
\hline P11 & Cotton sold \\
\hline T1 & Starting transportation \\
\hline T2 & Sensors monitoring \\
\hline T3 & Raising the alarm \\
\hline T4 & Deciding to change the destination \\
\hline T5 & Uncoupling the wagon and unloading \\
\hline T6 & Delivering the cotton to the local market \\
\hline
\end{tabular}

The colour set is defined as follows:

colset weight $=$ int timed; colset pi $=$ string timed;

colset scost $=$ string timed;

colset wps $=$ product weight $*$ pi ${ }^{*}$ scost timed;

colset tcost $=$ string timed;

colset wpi = product weight $*$ pi timed;

colset dcost $=$ string timed;

colset $w t=$ product weight $*$ pi ${ }^{*} \operatorname{scost} * d \cos t * t \cos t$ timed;

var $w$ : weight; var $s$ : scost;

var $i$ : pi; vard: dcost; vart: tcost;

where

- weight represents the weight of the cotton, defined as an integer type.

- pi represents the humidity, defined as a character type.

- scost represents the cost incurred by the wagon uncoupling.
- wps is defined as the product color set, representing the product of cotton weight, humidity and wagon uncoupling cost

- tcost represents the transportation cost, defined as a character type.

- wpi is defined as the product color set, representing the product of cotton weight and humidity.

- dcost represents the cost incurred by cotton sale at a lower price, defined as a character type.

- wt is defined as the product color set, representing the product of cotton weight, humidity, wagon uncoupling cost, cotton discount cost, and transportation cost

- The variables $\mathrm{w}, \mathrm{s}, \mathrm{i}, \mathrm{d}$, and t belong to these color sets.

"Table IV" shows the time spent for the process tasks in the case of changing the destination.

TABLE IV. Time SPENT For the Process TASks When Changing the DESTINATION

\begin{tabular}{|l|l|}
\hline \multicolumn{1}{|c|}{ Task } & Time spent \\
\hline Transportaion from Urumchi to Lanzhou & 1 day \\
\hline Contacting the local logistics companies & 1 day \\
\hline Delivery to the local market & 1 day \\
\hline
\end{tabular}

As such, it will take 3 days for the adaptive process if the consigner decides to change the destination.

\section{DISCUSSION}

According to the above two models, the costs involved in the two processes are different, and the time required is very different, which can be divided into the following situations:

A. The Time Difference between the Two Processes Is Ignored When the Shipper Is Not Required to Transport the Time

In this case, the cost of reprocessing and continuing to transport is expressed in $\mathrm{C} 1$, and the cost of applying for change to the station is represented by $\mathrm{C} 2$. The formula is as follows:

$$
\begin{gathered}
C 1=\text { wagonuncouplingcost }+ \text { cottonrehandling cost }+ \text { tcost } \\
C 2=\text { wagonuncouplingcost }+ \text { discountcost }+ \text { tcost }
\end{gathered}
$$

If $\mathrm{C} 1$ is greater than $\mathrm{C} 2$, the shipper shall choose to apply for the change to the station. If $\mathrm{C} 1$ is less than $\mathrm{C} 2$, the shipper will continue to transport after processing.
B. The shipper has a higher time requirement, and the Time Cost Should Be Added to the Total Cost

The cost formula for $\mathrm{C} 1$ and $\mathrm{C} 2$ is shown below:

$$
\begin{aligned}
& C 1=\text { wagonuncoupling ciost }+ \text { cottonrehandling cost }+ \text { tcost }+ \text { timecost } \\
& C 2=\text { wagonuncoupling cost }+ \text { discountcost }+ \text { tcost }+ \text { timecost }
\end{aligned}
$$


It is obvious that timecost (continue to transport) is greater than timecost (change to the station), because it takes 6 days to continue the transportation after processing, and it only takes 3 days for the application to change to the station. D1 denotes the sum of wagon uncoupling cost, cotton rehandling cost and transportation cost, and D2 represents the sum of wagon uncoupling cost, discount cost and transportation cost. D3 represents the difference between the time cost of continuing to transport and the time cost of the change to the station.

- If D1 is greater than D2, C1 is greater than C2. The shipper should choose to change to the station.

- D1 is less than D2.

If the difference between D2 and D1 is less than D3, then $\mathrm{C} 1$ is greater than $\mathrm{C} 2$. The shipper should choose to apply for change to the station. If the difference between D2 and $\mathrm{D} 1$ is greater than D3, then $\mathrm{C} 1$ is less than C2. The shipper should choose to continue the transport after reprocessing.

From the above analysis, we can see that when an emergency occurs, customers can have multiple process choices in the Internet of Things environment. This provides a good basis for decision-making. And the article suggests that you can expand customer resources in order to reduce losses.

\section{CONCLUSION}

Based on the application of the Internet of Things technology in railway freight transportation, this article studies the logistics process under the Internet of Things technology. The article takes transportation cotton as an example and uses the Internet of Things technology to build a transportation monitoring system. In addition, the emergency situation during transportation was simulated. The transportation process was modeled using colored Petri mesh, and the flow optimization scheme was given. Suggestions for improvement were proposed. Using the Internet of Things technology to effectively transform the logistics data in transportation into useful logistics information, providing support for decision-making in the logistics enterprise sector, and this also promotes the development of the Internet of Things technology in the railway transportation industry.

\section{REFERENCES}

[1] Hollweg, C. and M.H. Wong, Measuring Regulatory Restrictions in Logistics Services. ERIA Discussion Paper Series, 2009(2009-14).

[2] Speranza, M.G., Trends in transportation and logistics. European Journal of Operational Research, 2016.

[3] Atzori, L., A. Iera, and G. Morabito, The internet of things: A survey. Computer networks, 2010. 54(15): p. 2787-2805.

[4] Bello, O. and S. Zeadally, Toward efficient smartification of the Internet of Things (IoT) services. Future Generation Computer Systems, 2017.

[5] Gregor, T., M. Krajčovič, and D. Więcek, Smart Connected Logistics. Procedia Engineering, 2017. 192:

[6] Siror, J.K., S. Huanye, and W. Dong, RFID based model for an intelligent port. Computers in industry, 2011.
[7] Mishra, D., et al., Vision, applications and future challenges of Internet of Things. Industrial Management \& Data Systems, 2016. 116(7): p. 1331-1355.

[8] Olson, N., J.M. Nolin, and G. Nelhans, Semantic web, ubiquitous computing, or internet of things? A macro-analysis of scholarly publications. Journal of Documentation, 2015. 71(5).

[9] Gallouj, F. and O. Weinstein, Innovation in services. Research policy, 1997. 26(4): p. 537-556.

[10] Reijers, H.A., Design and control of workflow processes: business process management for the service industry. 2003: Springer-Verlag.

[11] Jensen, K., L.M. Kristensen, and L. Wells, Coloured Petri Nets and CPN Tools for modelling and validation of concurrent systems. International Journal on Software Tools for Technology Transfer, 2007. 9(3-4): p. 213-254.

[12] Jensen, K., An introduction to the practical use of coloured Petri Nets. 1998: Springer Berlin Heidelberg. 237-292.

[13] Kristensen, L.M., S. Christensen, and K. Jensen, The practitioner's guide to coloured Petri nets. International Journal on Software Tools for Technology Transfer, 1998. 2(2): p. 98-132.

[14] Van der Veeken, D.J.M. and W.G.M.M. Rutten, Logistics service management: opportunities for differentiation. International Journal of Logistics Management, The, 1998. 9(2): p. 91-98.

[15] Chow, H.K.H., K. Choy, and W. Lee, A dynamic logistics process knowledge-based system-An RFID multi-agent approach. Knowledge-Based Systems, 2007. 20(4): p. 357-372.

[16] Wang, Y., et al., Acquiring logistics process intelligence: methodology and an application for a Chinese bulk port. Expert Systems with Applications, 2014. 41(1): p. 195-209.

[17] Schwab, K., The Fourth Industrial Revolution: What it Means, How to Respond. Economy Culture \& History Japan Spotlight Bimonthly, 2016.

[18] Jabbar, S., et al., Semantic Interoperability in Heterogeneous IoT Infrastructure for Healthcare. Sustainable Cities \& Society, 2017. 2017(1): p. 1-10.

[19] Lee, S.E., M. Choi, and S. Kim, How and what to study about IoT: Research trends and future directions from the perspective of social science. Telecommunications Policy, 2017.

[20] Wu Shuangshuang. Research on Railway Logistics Development Based on Internet of Things Technology[J]. Logistics Engineering and Management, 2011, 33(9):53-53

[21] Jensen, K., L.M. Kristensen, and L. Wells, Coloured Petri Nets and CPN Tools for modelling and validation of concurrent systems. International Journal on Software Tools for Technology Transfer, 2007. 9(3-4): p. 213-254.

[22] Zou Tingting, Chen Yan, Sun Guolei. Modeling of Goods Distribution Process Based on Colored Petri Nets[C] China Intelligent Transportation Annual Conference. 2006

[23] Wang Xiaobiao. Status and Countermeasures of Cotton Logistics in Xinjiang[J].Journal of Anhui Agricultural Sciences, 2010, 38(16):8712-8713

[24] Zhao Jie, Huang Huan, Lv Yingxi, et al. Design of Railway Dangerous Goods Transportation Monitoring System Based on RFID and WSN[J]. China Management Informationization, 2016, 19(2):165-166.

[25] Yan Ming. Class Classification and Code Table for Railway Freight Transport [J]. 